\title{
Revista Brasileira de Enfermagem REBEn \\ Atuação do enfermeiro no cuidado com o Cateter Central de Inserção Periférica no recém-nascido
}

\author{
Action of the nurse with Peripherally Inserted Central Catheter in the infant newborn \\ Actuación del enfermero en el cuidado con el Cateter Central de Inserción Periferica en \\ el recién nacido
}

\section{Zaira Simas Rodrigues}

Enfermeira assistencial da Unidade Neonatal do Hospital Geral de Fortaleza, CE. Especialista em Enfermagem Neonatológica.

Edna Maria Camelo Chaves

Enfermeira. Mestre em Saúde da Criança e do Adolescente pela Universidade Estadual do Ceará (UECE). Mestranda do Curso de Cuidados Clínicos em Saúde da UECE. Membro do Projeto de Pesquisa Saúde do Binômio Mãe e Filho/UFC, Fortaleza, CE. ednacam3@hotmail.com

\section{Maria Vera Lúcia Moreira Leitão Cardoso}

Enfermeira. Mestre e Doutora em Enfermagem pela UFC. Professora Adjunta do Departamento de Enfermagem da FFOE/UFC, Fortaleza, CE. Coordenadora do Projeto Saúde do Binômio Mãe e Filho/UFC. cardoso@ufc.br

\section{RESUMO}

Os avanços tecnológicos em Neonatologia vêm beneficiando os recém-nascidos que necessitam de um acesso venoso seguro. Objetivou-se investigar a atuação do enfermeiro no cuidado com o Cateter Central de Inserção Periférica (PICC) na Unidade de Terapia Intensiva Neonatal em Fortaleza, CE. A amostra foi composta por 17 enfermeiros e os dados foram coletados de julho a agosto/2004 através de questionário estruturado. Nos resultados verificou-se que 09 citaram a veia basílica como a mais indicada para a punção; 17 mencionaram a lavagem das mãos antes e após o manuseio e a lavagem do cateter antes e após as medicações como os cuidados mais importantes. Conclui-se que o manuseio deste dispositivo requer conhecimento e habilidade por parte dos profissionais.

Descritores: Cateterismo periférico; Recém-nascido; Cuidados de enfermagem.

\section{ABSTRACT}

Technological advances in Neonatology have benefited the infant newborn who need a safe venous access. This study aimed at investigating the actions of the nurse regarding Peripherally Inserted Central Catheter (PICC) in the Neonatal Intensive Care Unit in Fortaleza, CE. The sample was composed by 17 nurses; the data were collected from July to August 2004 through a structured questionnaire. In the results, it was verified that 09 nurses reported the basilic vein as the most indicated for puncture; 17 reported the washing the hands before and after handling the catheter and washing it before and after the drug administration as the most important care. It was concluded that handling this device requires knowledge and hability on the part of the professionals.

Descriptors: Catheterization, peripheral; Infant newborn; Nursing care.

\section{RESUMEN}

Los avances tecnológicos en la Neonatología han beneficiando los recién nacidos de alto riesgo, que necesitan de un acceso venoso seguro. Este trabajo tuvo por objetivo investigar la actuación del enfermero en el cuidado con el Cateter Central de Inserción Periférica (PICC) en la Unidad de Terapia Intensiva Neonatal en Fortaleza, CE. Los datos fueron recolectados de julio a agosto de 2004 a través de un cuestionario. En los resultados se verificó que 09 citaron la vena basílica como de más indicada para la punción; 17 mencionaron de entre los cuidados, el lavado de las manos antes y después de lo manoseo y el lavado del cateter antes y después de las medicaciones como los más importantes. Se concluye que lo manoseo de este dispositivo requiere conocimiento y habilidad por parte de los profesionales.

Descriptores: Cateterismo periferico; Recién nacido; Atención de enfermería.

Rodrigues ZS, Chaves EMC, Cardoso MVLML. Atuação do enfermeiro no cuidado com o Cateter Central de Inserção Periférica no recém-nascido. Rev Bras Enferm 2006 set-out; 59(5): 626-9.

\section{INTRODUÇÃO}

De 1980 a 2000, intensificaram-se os avanços tecnológicos em terapia intravenosa na Neonatologia, beneficiando os recém-nascidos (RN) de alto risco que necessitam de um acesso venoso seguro, por um tempo prolongado, visando à administração de drogas vasoativas e irritantes, soluções hidroeletrolíticas, nutrição parenteral e antibióticos.

Autilização desta terapêutica apresenta determinadas peculiaridades práticas que vão desde a escolha do vaso sanguíneo até a manutenção do acesso. Por isso é importante que o enfermeiro tenha conhecimentos básicos em relação à fisiologia e à anatomia da rede venosa. Após o nascimento, a limitação venosa é condicionada pelo organismo do $\mathrm{RN}$, ainda em fase de crescimento e desenvolvimento, o que pode
Submissão: $17 / 11 / 2005$ Aprovação: 03/05/2006 
influenciar no aparecimento de sérios transtornos à manutenção dessa terapêutica.

O procedimento da punção venosa é uma das práticas mais difíceis de realizar no neonato. Além disso, a perda do acesso venoso freqüentemente causa interrupções na infusão de líquidos e eletrólitos, comprometendo a eficácia da terapêutica. As repetidas venopunções comprometem os vasos periféricos com certas complicações, que podem ser locais ou sistêmicas, culminando muitas vezes com a necessidade de uma dissecção venosa ${ }^{(1,2)}$

Os dispositivos periféricos utilizados são os cateteres montados sobre agulha, os cateteres periféricos de curta duração e os Cateteres Centrais de Inserção Periférica (PICC).

No momento atual, os PICCs são indicados para todo RN que necessite de terapia intravenosa por um período superior a seis dias, sendo que o tempo de permanência é oito semanas em média ${ }^{(3)}$. A composição do PICC pode ser de poliuretano ou elastômeros de silicone, que são materiais biocompatíveis, menos trombogênicos, que dificultam a agregação de microorganismos em sua parede ${ }^{(3)}$

Os PICCs são inseridos por enfermeiros capacitados e médicos neonatologistas habilitados para realizar o procedimento à beira do leito. Estes dispositivos foram aprimorados para uso em Neonatologia devido ao pequeno diâmetro do cateter e da flexibilidade do material.

A partir dos anos 90 do século XX, no Brasil, têm-se utilizado cada vez mais os PICC, principalmente em RNs ${ }^{(1)}$.

Neste contexto, insere-se a terapia intravenosa como recurso terapêutico para uma clientela específica, que necessita de uma abordagem diferenciada para a prática da enfermagem neonata( ${ }^{(4)}$.

Diante deste fato, o cuidado com o PICC é garantia de um acesso venoso confiável para o recém-nascido internado, que necessita da administração de soluções e medicamentos, cabendo à equipe de enfermagem, cada vez mais, a capacitação teórica e prática concomitante com o avanço tecnológico crescente.

\section{OBJETIVO}

Investigar a atuação do enfermeiro no cuidado com PICC em recémnascidos de alto risco em uma unidade neonatal.

\section{MÉTODO}

Trata-se de um estudo do tipo descritivo-exploratório, para avaliar a atuação dos enfermeiros sobre o uso do PICC. Estes estudos são feitos em campo, em locais de convívios sociais como hospitais, clínicas, unidades de tratamento intensivo e comunidades(5).

Selecionou-se a Unidade de Terapia Intensiva Neonatal (UTIN) de um hospital público, credenciada pelo Sistema Único de Saúde (SUS), composta por 25 leitos, 12 de alto risco e 13 de médio risco, que é referência para o atendimento de alto risco.

A população foi composta por 20 enfermeiros lotados na referida unidade. A amostra foi constituída por todos os 17 enfermeiros assistenciais que trabalhavam nesta unidade, nos turnos da manhã, tarde e noite, responsáveis pela manutenção, remoção do cateter e que auxiliam na inserção do PICC que é feita por um dos membros da equipe de cateteres, a qual é composta por duas enfermeiras e duas médicas neonatologistas habilitadas para realizar 0 procedimento.

\section{Instrumento de coleta de dados}

Os dados foram coletados por meio de um questionário com perguntas abertas e fechadas nos turnos e horários concordantes com a escala de trabalho de cada participante. Foram abordadas questões sobre a utilização, os cuidados e a manutenção do PICC, e foi aplicado nos meses de julho e agosto de 2004.

Quanto aos aspectos éticos, o estudo foi aprovado pelo Comitê de Ética em Pesquisa da instituição pesquisada atendendo à Resolução 196/96, sobre pesquisas que envolvem seres - humanos, do Conselho Nacional de Saúde/ Ministério da Saúde, tendo sido aprovado conforme o protocolo n ${ }^{\circ}$ 072106-04 de 21/07/2004. Solicitamos por escrito mediante termo de livre consentimento a participação dos enfermeiros no estudo. Foi resguardada a identidade e preservou-se o anonimato dos participantes.

Os dados foram tratados pela estatística descritiva em números absolutos, apresentados em quadros e discutidos conforme literatura pertinente ao tema.

\section{RESULTADOS E DISCUSSÃO}

No período do estudo, foram entrevistadas 17 enfermeiras que atuam no Serviço de Neonatologia nos diferentes turnos, prestando assistência aos RNs internados na UTIN e que ficam responsáveis pela monitorização dos PICC. Em relação à faixa etária, sete está entre 20 a 30 anos, seis entre 31 e 40 anos, quatro acima de 40 anos. Constatamos um perfil de enfermeiros jovens dentro de um ambiente especializado. Vale ressaltar a importância das vivências adquiridas com o passar dos anos por parte dos profissionais, uma vez que as instituições buscam na contratação de recursos humanos, basicamente, conhecimento, habilidade, saúde e disponibilidade para as atividades $^{(6)}$.

Em relação ao tempo de formação, encontramos 11 enfermeiras com menos de 10 anos; seguidas de quatro entre 10 e 20 anos e duas acima de 20 anos. Quando analisamos o tempo de serviço dentro da unidade, encontramos 11 enfermeiras no intervalo menor do que 10 anos seguidas de seis dentro do intervalo de 10-20 anos. Faz-se necessário um constante incentivo para manter o entusiasmo dentro de um setor com alto nivel de complexidade, onde o tecnicismo presente não se deve sobrepor ao humano.

Dentre estes, 12 enfermeiros têm curso de especialização, enquanto 05 ainda permanecem somente com a graduação. Diante dos dados, podemos constatar que a qualificação, apesar das dificuldades como o baixo salário, jornada de trabalha longa, falta de incentivo das instituições não foi um empecilho para os que buscam capacitação. Os cursos de especialização têm a finalidade de aprofundar os conhecimentos teóricos e práticos de uma área limitada do saber e da profissão, a fim de capacitar o profissional, tornando-o especializado(7).

No quadro 1 estão apresentados os resultados que abordam o conhecimento do enfermeiro na atuação com o PICC no recém-nascido de alto risco.

Relativo à indicação do acesso central, obtivemos mais de um item como resposta, sendo 11 por acesso venoso precário, seguidos de 10 por necessidade de um acesso por um período superior a seis dias e três por necessidade do acesso por mais de 12 meses.

Todo recém-nascido que necessite de infusão hidroeletrolítica por um período superior a 06 dias tem indicação de um $\mathrm{PICC}^{(3,8)}$. Este deve ser a primeira escolha, desde que o recém-nascido tenha condições clínicas, como boa perfusão periférica, normotérmico, hidratado, com saturação de oxigênio acima de $90 \%$. Este procedimento deve ser eletivo, não podendo ser realizado em situação de urgência.

O enfermeiro, ao selecionar o tipo de dispositivo intravenoso que será usado, deverá considerar o tratamento a ser realizado, a condição clínica do recém-nascido e a disponibilidade do material e pessoal(1,2). Diferente das dissecções venosas o PICC é deve ser instalado logo que o RN tenha condição para ser submetido ao procedimento, quando a rede venosa ainda estiver preservada, pois a presença de hematomas decorrentes das punções venosas anteriores, dificultam a progressão do cateter de silicone.

As veias de eleição para inserção do PICC citadas pelas participantes foram: nove na basílica; cinco na antecubital mediana; três na antebraquial mediana; uma cefálica e uma sem resposta. Salientamos que alguns enfermeiros responderam mais de um item nesta questão.

A veia basílica, por ter uma anatomia favorável, ser calibrosa e ter um menor número de válvulas tem sido a mais citada nos estudos, seguida da veia cefálica ${ }^{(3,8,9)}$. A sua localização facilita a manipulação durante a troca do curativo e dos dispositivos utilizados para melhorar a acurácia da terapia 


\begin{tabular}{|c|c|}
\hline Indicação da instalação & $\mathbf{n}$ \\
\hline Acesso venoso precário & 11 \\
\hline Necessidade do acesso central por mais de 12 meses & 03 \\
\hline Necessidade do acesso central por mais de 06 dias & 10 \\
\hline 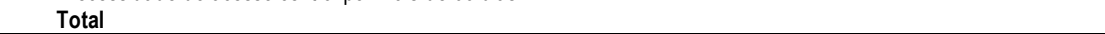 & 24 \\
\hline Local da instalação & $\mathrm{n}$ \\
\hline Cefálica & 1 \\
\hline Basilica & 9 \\
\hline Antecubital mediana & 5 \\
\hline Antebraquial medicana & 3 \\
\hline Nenhuma resposta & 1 \\
\hline Total & 19 \\
\hline Cuidados com o PICC & $\mathrm{n}$ \\
\hline Troca de curativos com 7 dias ou quando necessário & 15 \\
\hline Lavar o PICC antes e após medicações com água destilada & 17 \\
\hline Lavar O PICC 3 vezes ao dia & 05 \\
\hline Realizar raio-x após a inserção para visualizar a ponta do cateter & 15 \\
\hline Trocar torneiras no máximo com 48 horas & 13 \\
\hline Lavar as mãos antes e após o manuseio com o PICC & 17 \\
\hline Não utilizar seringas menores do que $10 \mathrm{ml}$ & 03 \\
\hline Limpar as torneiras antes do manuseio com álcool á $70 \%$ & 15 \\
\hline Total & 100 \\
\hline Finalidades do curativo & $\mathrm{n}$ \\
\hline Proporciona um ambiente estéril para o cateter & 13 \\
\hline Previne migração do cateter & 06 \\
\hline Evita danificação do cateter & 12 \\
\hline Renova a qualquer momento desde que as bordas estejam soltas ou a película não ofereça segurança para o cateter & 14 \\
\hline Nenhuma resposta & 01 \\
\hline Total & 46 \\
\hline Atitudes dos enfermeiros diante das complicações & $\mathrm{n}$ \\
\hline Retira imediatamente o PICC & 02 \\
\hline Solicita raios- $X$ & 07 \\
\hline Suspende a infusão & 05 \\
\hline Investiga a causa & 15 \\
\hline Total & 29 \\
\hline
\end{tabular}

Quadro 1. Conhecimentos dos enfermeiros na atuação com o PICC no recém-nascido de alto risco. Fortaleza, 2004.

intravenosa. Os sítios mais freqüentes de inserção do PICC foram: veia basílica, $56,6 \%$; veia cefálica, $25 \%$; veia metacarpiana, $3 \%$; veia pedial, $1,2 \%$;e entre as veias safena interna e externa $1 \%(10)$.

Observamos nos resultados que ainda há desconhecimento na veia de eleição, pois a veia cefálica obteve apenas uma resposta. A veia basílica é a mais utilizada, seguida da veia cefálica, quando a rede venosa está preservada. A busca por outros locais de inserção é decorrente da rede venosa limitada, freqüentemente presente no recém-nascido prematuro, em virtude das punções para terapia intravenosa e para coleta de sangue para os exames laboratoriais.

Todos os itens citados como cuidados com o PICC são imprescindiveis ao tratamento com o PICC, razão pela qual foi obtido mais de um item como resposta. Em relação ao cuidado, dois itens foram citados por todos os entrevistados, a saber: 17 vezes lavar o PICC com água destilada antes e após a medicação e lavar as mãos antes e após o manuseio com o PICC seguidos de 15 respostas da troca de curativos a cada 07 dias; da realização de raio-X após a inserção do cateter e da limpeza das torneiras com álcool a $70 \% ; 13$ relatos da troca de torneiras; 05 da lavagem do cateter 03 vezes ao dia e 03 relatos do uso de seringas de $10 \mathrm{ml}$.

Percebemos que, apesar de reconhecerem a importância de lavar 0 PICC antes e após a medicação, o mesmo não ocorre em relação à lavagem do cateter no início de cada turno, quando o recém-nascido é manuseado, a fim de identificar complicações, como obstrução por falta de infusão ou por interação de medicamentos, que precipitam ocluindo a luz do cateter.

Em nossa vivência dentro da unidade após elaboração e operacionalização do protocolo de cateter observamos a melhoria da qualidade do cuidado prestado na assistência.

A manutenção está relacionada com o cuidado dispensado durante a assistência. A infusão deve ser contínua, uma vez que não utilizamos a solução de heparina para manter o cateter pérvio. Asalinização do cateter deve ser feita com uma seringa de $10 \mathrm{ml}$, que tem menor pressão, reduzindo o risco de rompimento acidental do cateter ${ }^{(11,12)}$.

No que diz respeito ao curativo do PICC, os participantes consideraram mais de uma opção como importantes, quando marcaram as respostas por considerarem corretas. A troca do curativo por falta de integridade da película foi citada 14 vezes, seguida de proporcionar um ambiente estéril 13-vezes; evita a danificação do cateter - 12 vezes; previne a migração do cateter - 06 vezes e 01 sem resposta.

A maioria das participantes em relação à fixação do cateter respondeu em consonância com a literatura, pois o cateter deve ficar fixo à pele com uma película transparente, que seja impermeável aos microorganismos e que permita a evaporação da água. No momento atual, a orientação para recém-nascidos é que a troca deve ser feita quando as bordas estiverem soltas ou o curativo sujo de sangue ${ }^{(3,12)}$. Os enfermeiros ficam responsáveis pela observação da integridade do óstio de inserção para a detecção precoce de complicações.

A manipulação mínima faz-se necessária, pela facilidade com que pode ocorrer o deslocamento acidental do cateter durante a troca do curativo, além de assegurar menor trauma na epiderme do neonato, mantendo a integridade cutânea muitas vezes comprometida pela própria imaturidade do sistema.

Outra vantagem para o recém-nascido é que a película permite inspecionar diariamente o local de inserção, o trajeto do cateter, os sinais de infiltração e edema, isquemia e infecção ${ }^{(9)}$.

Neste contexto, é imprescindível o papel do enfermeiro, o qual fica responsável pela escolha do tipo de curativo a ser utilizado dentro da unidade, bem como pela realização do procedimento técnico. Cabe ao profissional de enfermagem a vigilância continua para detecção de alterações relacionadas à infecção da corrente sanguínea, uma vez que este permanece a maior parte do tempo prestando assistência ao cliente ${ }^{(13)}$.

No que diz respeito ao curativo do PICC, os participantes consideraram mais de uma opção como importantes, quando marcaram as respostas por considerarem corretas. A troca do curativo por falta de integridade da película foi citada 14 vezes, seguida de proporcionar um ambiente estéril 13-vezes; evita a danificação do cateter -12 vezes; previne a migração do cateter - 06 
vezes e 01 sem resposta.

Quanto à fixação do cateter, a maioria das participantesrespondeu em consonância com a literatura, pois o cateter deve ficar fixo à pele com uma película transparente, que seja impermeável aos microorganismos e que permita a evaporação da água. No momento atual, a orientação para recémnascidos é que a troca deve ser feita quando as bordas estiverem soltas ou o curativo sujo de sangue ${ }^{(3,12)}$. Os enfermeiros ficam responsáveis pela observação da integridade do óstio de inserção para a detecção precoce de complicações.

Amanipulação mínima faz-se necessária, pela facilidade com que pode ocorrer o deslocamento acidental do cateter durante a troca do curativo, além de assegurar menor trauma na epiderme do neonato, mantendo a integridade cutânea muitas vezes comprometida pela própria imaturidade do sistema.

Outra vantagem para o recém-nascido é que a película permite inspecionar diariamente o local de inserção, o trajeto do cateter, os sinais de infiltração e edema, isquemia e infecção $0^{(9)}$.

Neste contexto, é imprescindível o papel do enfermeiro, o qual fica responsável pela escolha do tipo de curativo a ser utilizado dentro da unidade, bem como pela realização do procedimento técnico. Cabe ao profissional de enfermagem a vigilância continua para detecção de alterações relacionadas à infecção da corrente sanguínea, uma vez que este permanece a maior parte do tempo prestando assistência ao cliente ${ }^{(13)}$.

Diante das complicações do PICC, 15 respostas foram marcadas para a investigação da causa; 07 para a solicitação raios- $X ; 05$ suspensão da infusão e 02 para a retirada do cateter imediatamente. Os enfermeiros consideraram mais de uma resposta neste item por considerarem importante.

Os profissionais sentem dificuldades em investigar as causas das complicações, pois esta situação é vivenciada no quotidiano da UTIN . A falta de infusão contínua leva à obstrução do cateter que culmina com uma desobstrução ineficaz, ocasionando a perda, em razões da complexidade que envolve a remoção de coágulos em um cateter de diâmetro interno pequeno. Outro problema freqüente no RN é a presença de edema por hipoalbuminemia, que leva muitas vezes à remoção precoce deste por suspeita de infiltração. Para confirmação do posicionamento da ponta do cateter em um vaso central, faz-se necessária a realização de um raio-X de controle.

A manutenção segura do cateter reduz o risco de perda antes do término do tratamento. A escolha da solução utilizada para esse fim é a salina a $0,9 \%$. Para assegurar a permeabilidade do cateter, este deve ser testado por turno por um membro da equipe de enfermagem.

Diante desta incorporação tecnológica, deve ser um compromisso moral da enfermagem conduzir a terapia intravenosa da forma mais eficiente e menos traumática para o $\mathrm{RN}^{(14)}$.

\section{CONCLUSÃO}

O PICC nos serviços de Neonatologia está se tornando mais freqüente, apesar do pouco tempo de uso desta tecnologia dentro das unidades de alto risco. Por ser um dispositivo novo, a necessidade de qualificação dos profissionais se faz necessária para garantir a qualidade na assistência. Observamos lacunas na fundamentação teórico-prática dos enfermeiros que prestam assistência. Em relação à indicação do PICC foram obtidas 11 respostas de acesso venoso precário. A veia de escolha foi à basílica com nove indicações. Entre os cuidados com o PICC a lavagem das mãos e a lavagem do cateter antes e após a medicação foram citadas por todos os participantes. Diante das complicações a atitude dos enfermeiros foi investigar a causa em 15 respostas. 0 ambiente estéril do curativo foi citado 13 vezes nas respostas. Conclui-se que o manuseio deste dispositivo requer conhecimento, destreza e habilidade por parte dos enfermeiros e membros da equipe de saúde.

\section{REFERÊNCIAS}

1. Lourenço SA, Kakehashi TY. Assistência de enfermagem pré e pós - inserção imediata do cateter venoso central de inserção periférica em pacientes neonatal. Nursing 2003; 63: 24.

2. Phillips LD. Manual de terapia intravenosa. $2^{\mathrm{a}}$ ed. Porto Alegre (RS): Artmed; 2001.

3. Centers for Diesase Control and Prevention. Departament of Health and Human Services. Intravascular device - related infections preventions; guidelines availability: notice. Atlanta (GO): CDC; 2002.

4. Silva GRG, Nogueira MFH. Terapia intravenosa em recémnascidos. Rio de Janeiro (RJ): Cultura Médica; 2004.

5. Polit DF, Hungler BP. Fundamentos de pesquisa em enfermagem. $3^{\text {a }}$ ed. Porto Alegre (RS): Artes Médicas; 1995.

6. Aquino KS. Rotatividade das enfermeiras. Hospital, Administração e Saúde 1992; 16(2): 74.

7. Barros SMO, Ribeiro CA, Sumita SLN, Cunha ICKO, Granitoff N, Abrahão ARB, et al. Pós-Graduação lato- sensu em Enfermagem na Universidade Federal de São Paulo. Acta Paul Enferm 1998; 11(esp): 17-21.

8. Richtmann R, Silva LPS, El-Far F, Amarante JMB, Kawagoe JY, Konkewicz LR, et al. Diagnóstico e prevenção das infecções hospitalares em neonatologia. São Paulo (SP): APECIH; 2002.
9. Chaves EMC. Redução da infecção da corrente sangüínea através do filtro bacteriológico em prematuros (dissertação). Fortaleza (CE): Universidade Estadual do Ceará; 2003.

10. Herrera CR, Mayor SJ, Vasquez TML. El cateter venoso percutâneo: uma opcion económica y segura para niños pretérmino de muy bajo peso. Colômbia Méd 1996; 27: 11-51.

11. Pezzi MO, Peruzzo AB, Araújo AMP, Moraes ET, Yoshimoto LT, Sanches MO, et al. Manual de cateterização central de inserção periférica CCIP/PICC. Porto Alegre (RS): Edelbra; 2004.

12. Tamez RN, Silva MJP. Enfermagem na UTI neonatal. $2^{\mathrm{a}}$ ed. Rio de Janeiro (RJ): Guanabara Koogan; 2002.

13. Centers for Diesase Control and Prevention. Departament of Health and Human Services. Intravascular device - related infections preventions; guidelines availability: notice. Atlanta (GO): CDC; 2004.

14. Leite JL, Dantas CC, Fonseca JM, José SP, Stipp MAC. A enfermagem prevenindo e cuidando das complicações locais decorrentes do uso de cateter venoso periférico em pacientes com HIV/AIDS. Rev RENNE 2004; 5(1): 41-8.

15. Nascimento EMF. Sistema fechado para infusão venosa: por quê? Nursing 2000; 3(27): 20-5. 